\title{
Faculty Reflections on Decision-making and Pedagogical Use of Online Activities in Teacher Education
}

\author{
Swapna Kumar, Ed.D. \\ School of Teaching and Learning \\ University of Florida, Gainesville, USA \\ swapnak@ufl.edu
}

\begin{abstract}
Teacher educators preparing their students for $21^{\text {st }}$ century schools are increasingly using online technologies in on-campus courses. While some teacher educators have used such activities for almost a decade and have migrated from learning management systems to wikis and blogs, others still struggle to structure and facilitate online activities effectively. Ten teacher educators' decisions to use online activities in 23 face-to-face courses based on several criteria (class size, instructional goals, course type, students' prior knowledge, and the content of classroom instruction) are described in this chapter. Faculty member's reflections on their decisions, practical examples from different courses that they taught, and strategies they refined over time illustrated their focus on pedagogy as they migrated to newer technologies. The structure, design, and implementation of online activities discussed in this chapter could be useful to beginning educators, teacher developers, and instructional designers engaged in the integration of new technologies in higher education.
\end{abstract}

Keywords: asynchronous communication, blog, wiki, teacher education, online activities, higher education, decision-making, faculty, reflection, online discussion, web-enhanced instruction, student interaction, online groups, class size, technology, technology adoption

Teacher educators preparing their students for the schools of tomorrow are constantly faced with the challenge of staying informed about new technologies. They not only experiment with new technologies in order to be able to find tools and strategies that fit their own teaching style and instructional goals, but also attempt to model thoughtful use of technology that will prepare their students to teach with the new technologies that are available in the schools. Notwithstanding time constraints and the rapid changes in technology, teacher educators would like to communicate proven pedagogical strategies to their students while immersing them in the technology of the time. Text-based online communication is currently used widely by faculty in courses in higher education, (e.g. in learning management systems, blogs, wikis, and more recently social networking sites), but many faculty still struggle with how to put online communication to best use for student learning. Even as they integrate online activities into their on-campus courses, they constantly experiment in order to make informed decisions about best practice. 
The focus of this chapter is on faculty planning, guidance, and facilitation using online communication tools for student learning and student interaction in face-to-face courses, which can be transferred to other online technologies that are being introduced in teacher education courses. Online bulletin boards, discussion boards or forums have been used for over a decade to facilitate student interaction in higher education. An increasing number of teacher education faculty routinely use such tools in on-campus courses, and are now attempting to design similar activities with newer technologies like blogs, wikis, and social networking tools. Although most research studies explore the use of new technologies in education before those technologies become part of the mainstream, the purpose of this study is to focus on best practice by studying faculty members who have used both old and new online technologies in multiple courses over a period of time. On the one hand, their reflections on their practice and the changes in their teaching can inform other educators who are not as experienced in using these technologies. On the other hand, best practice from the use of online discussion boards and online collaborative activities can be adapted and transferred to newer technologies.

The chapter presents the experiences of ten teacher education faculty members who experimented with online student activities in different ways to model technology use as well as achieve their instructional goals in 23 courses. It provides practical examples of online activities by teacher educators but also empirical data in the form of faculty reflections on their use of those technologies and how they made changes in consequent iterations of a course based on experience. A description of faculty use of online activities as well as the identification of the factors that play a role in their decisions to modify or change these activities in each course will benefit practitioners and teacher educators who would like to apply new technologies. Researchers seeking to understand why and how faculty members use online technologies for instruction might also find the results informative. The chapter begins with an overview of the research on teaching with online communication tools and a description of the research methodology, followed by a description of the ways in which faculty used online communication tools for pre-class, post-class, and supplemental instruction. A discussion of faculty considerations when implementing and adapting online activities in each course that they taught, and guidelines for practitioners seeking to integrate online activities are provided at the end of the chapter. The term 'online interactions' in this study refers to asynchronous online interactions between students and the professor or among students while using a discussion board within a learning management system, a wiki, or a blog to supplement classroom instruction.

\section{RESEARCH ON ASYNCHRONOUS ONLINE COMMUNICATION IN HIGHER EDUCATION}

Garrison, Anderson and Archer (2000) posited that communities of inquiry, both face-to-face and online, consist of three elements: cognitive presence, social presence, and teaching presence, all three of which, they argue, are "crucial prerequisites for a successful higher education experience" (p87). In studying the effective use of online interactions for student learning, they also asserted that a participant's cognitive presence is the most important factor that influences his/her learning. They defined cognitive presence as ".. the extent to which the participants in any particular configuration of a community of inquiry are able to construct meaning through sustained communication" (p89) and stated that learners construct experiences and knowledge by analyzing the subject matter, raising questions, challenging assumptions, and integrating diverse ideas. In a later article, Garrison and Kanuka (2004) claimed that just as oral critical discourse can facilitate critical thinking, the reflective and explicit nature of online textbased communication is extremely conducive to higher-order cognitive learning. The process of writing helps to facilitate reflective thinking about problems, to formulate and clarify ideas, to organize thoughts, and to develop critical thinking which is fundamental to communities of inquiry (MacArthur, 2006). 


\section{Benefits of asynchronous online communication in higher education}

The use of asynchronous online discussions or computer-mediated communication (CMC) in oncampus courses has been reported to increase student participation and interaction, to provide increased opportunities for engaging with course content, expose students to multiple perspectives, contribute to a better understanding of course concepts, and facilitate the application of new and existing knowledge (Angeli, Bonk, \& Valanides, 2003; Biesenbach-Lucas, 2003; Dietz-Uhler \& Bishop-Clark, 2002; Fauske \& Wade, 2003; Gorski, Heidlebach, Howe, Jackson, \& Tell, 2000; Hara, Bonk \& Angeli, 2000; Kumar, 2007; Meyer, 2002; Schaff, 2003; Slavit, 2002; Vaughan \& Garrison, 2005; Young, 2002). Teacher education researchers have concluded that asynchronous online communication fosters reflection on teaching and learning, student engagement with course concepts, and increased student communication (Barnett, 2006; Ferdig \& Roehler, 2004; Kian-Sam \& Lee, 2008; Hough, Smithey \& Evertson, 2004; Jenning, 2005; Jetton, 2004; Lee-Baldwin, 2005; Lord \& Lomicka, 2007; Maher \& Jacob, 2006). In addition to enabling students to reflect on their teaching beliefs and teaching styles, and exposing them to multiple perspectives, integrating asynchronous online discussions in teacher preparation provides preservice teachers with technology skills that can be useful to them later in their teaching practice (Jetton, 2004; Lord \& Lomicka, 2007). Further, Ferdig and Roehler (2004) stated that "students who used discussion forums... were more likely to achieve understandings of teaching and learning that went beyond just a surface level" (p131).

The research reviewed also indicated that interactions in the classroom can be positively influenced by online interactions (Vess, 2005). While Dietz-Uhler and Bishop-Clark (2001) concluded that online discussions can be beneficial to "subsequent face-to-face discussions with the same people, assuming that the two discussions are temporally close" (271-272), Kumar (2007) reported on a professor's creation of a synergy between online and classroom discussions leading to enhanced student understanding of course topics in an undergraduate course. Garrison and Anderson (2003) argued for a blended learning environment that has a creative and well-designed discussion board. They claimed that instructors can best achieve higher-order learning by combining the energy and social interaction in a classroom with the increased response time and the resultant reflective dialog of an online discussion environment.

\section{Factors influencing outcomes of online activities in on-campus courses}

As with any use of technology in teaching practice, reflection or increased student engagement are not innate in the technology that is used but come about due to the strategies that faculty employ when using the technology. The question is how asynchronous online activities can be planned or structured by faculty to achieve the benefits described by the researchers cited above. Ferdig and Roehler (2004) suggest that the success of an online asynchronous discussion is influenced by multiple factors, including the relationship of discussion content to the course goals, and the modeling of discussion by the instructor. According to other researchers, the frequency and quality of student participation in online activities as well as the resulting knowledge construction are influenced by:

a) Instructor prompts or the nature of instructor questions

b) The subject-matter of the course or online activities

c) Instructor participation and guidance in online activities

d) Provision of structure and guidelines

e) The mandatory or optional nature of online activities

f) The task-related and non-task-related nature of online activities 
(Angeli, Valanides, \& Bonk, 2003; Christopher, Thomas, \& Talent-Runnels, 2004; Fauske \& Wade, 2003; Gilbert \& Dabbagh, 2005; Kumar, 2007; Oliver \& Trigwell, 2005; Schellens \& Valcke, 2006; Overbaugh, 2002; Wu \& Hiltz, 2004).

Similar factors have been found to influence student participation and learning when faculty use freely available blog and wiki software instead of the discussion board feature in learning management systems in higher education. Phillipson and Hamilton (2004) highlighted the importance of well-defined parameters to the success of a wiki that they designed, in which college students responded to annotations from poems using images, links, and author information. On experimenting with two different wikis that had different learning designs, tasks, and projects, Bower, Woo, Roberts and Watters (2006) concluded that task authenticity influences student contributions to wiki activities in a course. The contentcenteredness and structure of a wiki as well as planning by the instructor have been reported to contribute to the success of a wiki in graduate education (Engstrom \& Jewett, 2005; Raman, Ryan \& Olfman, 2005).

\section{Discussion of research on online interactions in higher education}

It follows that the ways in which an instructor structures, guides and participates in online activities contributes significantly to the success of such activities for student engagement and student learning. Course goals as well as the choices that instructors make when designing and participating in online activities could also be important. How do faculty members decide or plan their use of such online activities in teacher education courses? Do they use online activities in one particular way because it works for them, or do they adapt their activities according to the technology of the time and according to their prior experiences? Although the benefits and outcomes of computer-mediated communication or online interactions have been studied in the past, as have faculty perceptions and attitudes toward such technologies for instruction, the criteria that instructors consider when making choices and decisions to use online activities or use them in a certain way were not identified. Understanding how teacher education faculty currently use online technologies, the ways in which they have modified or adapted their use of the technology or their curriculum along the way and their perceptions of the resulting benefits to students can provide valuable insight for other educators who are also experimenting with asynchronous communication tools or online activities. This research was conducted to answer the following question:

What factors influence teacher educators' decisions to structure and facilitate online student activities (e.g. collaborative online assignments, online discussions) in their on-campus courses?

Faculty who use discussion boards, wikis, or blogs in more than one course are faced with decisions to structure and implement those technologies according to their course goals in each course. Teacher educators who use online discussions or online group activities in multiple courses that they teach were identified as an ideal sample to study this question, because it would be important to determine if they use online discussions or assignments in the same way or different ways in their teacher education courses.

\section{METHODOLOGY AND DATA COLLECTION}

Thirty-four teacher education faculty members in a large private university who had more than one course website listed each semester were contacted by email and provided with a description of the study. In order to exclude courses that used a learning management system, wiki, or a blog solely for presenting information and course materials to the students, faculty members were asked whether they included online discussions or activities by their students in their courses, whether they had done so for at least two years and in more than one course, and whether they used such activities in different ways. 
Fourteen faculty members who replied in the affirmative were contacted for semi-structured interviews. Ten faculty members who have their students interact in online discussion forums, blogs, and wikis finally participated in this research.

The ten faculty members had between four and twenty-six years of teaching experience and had been using online activities for two to four years in their undergraduate and graduate teacher education courses. They teach courses in foundations of education, educational policy, educational reform, physical education, history education, reading and writing education, special education, deaf studies, and instructional technology. At least one 60-minute semi-structured interview was conducted with each professor guided by the following topics:

- Faculty goals in integrating online activities into their on-campus courses

- The ways in which faculty have used/are using online activities in their on-campus courses

- Faculty reflections on the factors that influenced that use or on the ways in which they changed their use of online activities based on each experience.

The interview data were transcribed and managed using qualitative research software. Two interviews were coded by two doctoral students in addition to the researcher and the themes compared for inter-rater reliability. Cohen's kappa was calculated for inter-rater reliability between the researcher and each of the doctoral students and between the two doctoral students for the same two interviews. The results were between 0.6 and 0.8 , indicating a reasonably high agreement.

\section{FACULTY USE OF ONLINE ACTIVITIES IN TEACHER EDUCATION COURSES}

The teacher education faculty interviewed in this study cited several reasons for their initial use of online discussions in their courses: ensuring that students completed the readings $(n=8)$; wanting students to think about and be "engaged with course topics" when not in the classroom $(n=8)$; ensuring that all students participate and that "nobody hides" $(n=5)$; gauging student understanding of course material $(n=6)$; getting students to talk to one another instead of just to the professor $(n=5)$ and keeping students "connected" and "less isolated" during student-teaching $(n=4)$.

The faculty interviewed in this study used online discussion or online group activities in a learning management system, wiki, or blog in three ways: Pre-class (activities completed by students online before they met face-to-face weekly), Post-class (activities completed by students after they met face-to-face weekly), or as a supplement to classroom instruction (e.g. Online journals, online communications during student-teaching).

\section{Pre-class online activities}

Nine of ten faculty members interviewed in this study had used online activities (group tasks or online discussions) prior to weekly class meetings in undergraduate or graduate courses. In some cases, these activities were initiated by the instructor - professors provided a prompt, a question about readings, or a resource (online video/online link) to which students reacted. In other cases, students were required to post a prompt or lead the discussion for that week. For group activities, professors often provided clear instructions to students about what they should prepare in the group and present to the rest of the class in the online space. Four professors had students participate in online group activities related to the readings. For example, each group found an online video related to a topic from the readings, and posted it in the online discussion area along with a short summary of its relevance to the course. The group then prepared to answer questions from the instructor or peers in the classroom. In another instance, each group was 
asked to find an online research report with data pertaining to the weekly topic and post it along with a comment on its relevance.

Figure 1: Pre-class online activities

\begin{tabular}{|c|c|c|c|}
\hline $\begin{array}{ll}\text { Students } \\
- & \text { Complete } \\
& \text { readings } \\
- & \text { View online } \\
& \text { resources }\end{array}$ & 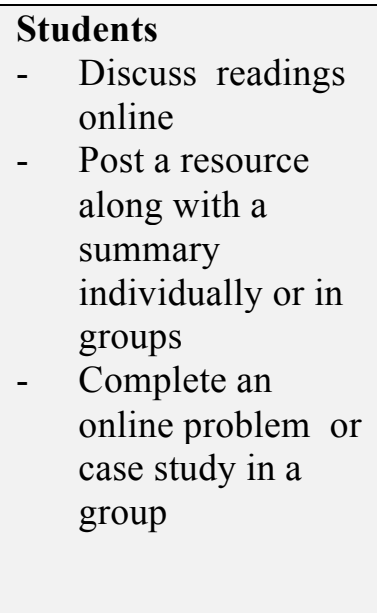 & $\begin{array}{ll}\text { Professor } \\
-\quad & \text { Prepares for class } \\
& \text { sessions based on } \\
& \text { student contributions } \\
\text { - } & \text { Clarifies problematic } \\
& \text { terms or topics } \\
- & \text { Steers "off-course" } \\
\text { discussions } \\
\text { - } \quad \text { Gauges student } \\
\text { understanding of course } \\
\text { topics } \\
\text { Identifies and helps } \\
\text { individual students with } \\
\text { problems }\end{array}$ & 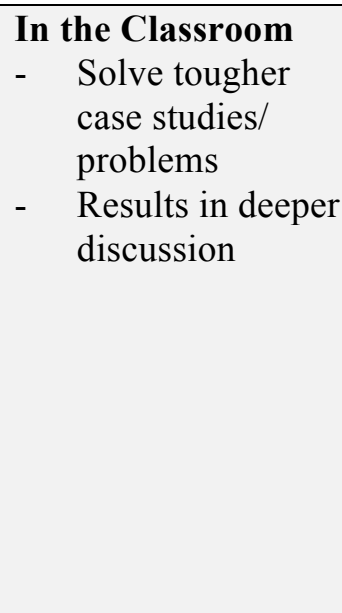 \\
\hline
\end{tabular}

The professors interviewed reflected that online discussion or group activities before a classroom session were extremely beneficial to them and to the students in several ways. Eight of them found that it helped both them and their students to prepare for classroom activities. One professor found it a good way to "break the ice" during the weeks when the course dealt with sensitive topics that students "got fired up about." He especially referred to one student who was very confrontational and whose participation in online discussions before a class had been helpful in preventing potential confrontations that could have taken up valuable class time. Another professor teaching a universal design course was able to provide students with easy contexts for problem-solving online and then raise the difficulty level of the problem in the class. Professors reflected that discussions could be taken to another level and that course topics were "initiated" online and "cemented" in the classroom.

Six professors stated that it helped them plan their classes better because the online activities exposed them to gaps in student knowledge. One professor said,

I tweak my lecture according to their comments, questions and concerns so that I am not second-guessing but really lining myself up with where they are at in their reading. It also gives me some sense of where we need more attention and more time and where they seem to be doing just fine. I pull out ideas that I want to encourage or discourage and I try to use them in the class.

Other professors similarly steered "off-course" discussions online, prepared comments or a summary of students' online discussions, and clarified problematic terms or topics that had arisen online, in the classroom. Three professors mentioned that they were able to identify and help students who had individual problems but who did not express themselves in the classroom. 


\section{Post-class online activities}

Figure 2: Post-class online activities

\begin{tabular}{|c|c|c|c|}
\hline $\begin{array}{ll}\text { Students } \\
- & \text { Complete } \\
& \text { readings } \\
- & \text { View online } \\
& \text { resources }\end{array}$ & $\begin{array}{l}\text { In the Classroom } \\
\text { - } \quad \text { Initial discussion on } \\
\text { topics } \\
\text { - } \quad \text { Professor /Guest } \\
\text { speaker } \\
\text { presentations } \\
\text { - } \quad \text { Students watch } \\
\text { video /analyze } \\
\text { cases or analyze } \\
\text { classroom } \\
\text { situations / solve } \\
\text { cases in groups }\end{array}$ & $\begin{array}{ll}\text { Professor } \\
\text { - } & \text { Provides additional } \\
\text { resources } \\
\text { - } & \text { Reflects and } \\
\text { comments on } \\
\text { classroom content } \\
\text { and interactions } \\
\text { - } & \begin{array}{l}\text { Provides prompt for } \\
\text { application/ synthesis } \\
\text { of weekly topic }\end{array}\end{array}$ & 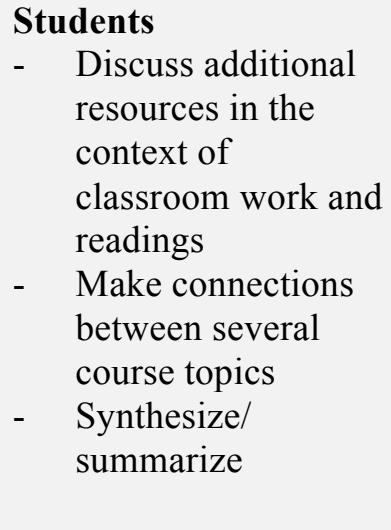 \\
\hline
\end{tabular}

Three of the ten faculty interviewed reported using online activities to engage students after a classroom session. One professor provided additional resources or summarized classroom discussion, "If we've spent a week talking about how students learn new vocabulary, that you know, we've spent the class session talking about that. Then I give them an article to extend their understanding of the topic, to further their thinking about other aspects of it." Another professor used questions and prompts to encourage students to "contextualize" and "apply" material that had been discussed in the classroom, sometimes getting students to work in groups on specific cases where different meanings could be attributed to the same word.

One of the benefits of post-class online discussions, according to one professor was that "Often times when it worked well, students were really able to make connections between the weeks. They began to see all the different topics in the context of educational policy, with basic elements that recurred." She used post-class activities to connect with students and synthesize topics in a class where a large number of lectures by guest speakers prevented student discussion of course topics. All three professors observed that some students who did not speak much in class took the opportunity to "make themselves heard" by taking notes in class and either posing questions or commenting online.

\section{Supplementing classroom instruction with online activities}

Four of the professors interviewed used a blog, a wiki, or an online discussion board for students to share and report on their field experiences or student teaching. These were courses that did not meet every week in the semester or where professors did not feel that the class meetings addressed students' individual challenges or concerns, so they used online space in the following ways:

- The professor created a password-protected wiki where each student had his/her own page to document and share his/her experiences teaching with technology. Students could comment and provide advice to each other.

- The professor created a password-protected blog where students posted weekly about their student-teaching experiences. 
- Students posted their weekly comments in an online discussion forum on: a) how their field experiences corresponded to course topics, b) how they observed application of concepts in the school classroom they were visiting, c) how teacher leaders they observed demonstrated certain behaviors or not.

- Students kept an online journal about their pre-practicum experiences that was passwordprotected to only the professor and that student.

The professors reflected that these activities were more challenging to implement as student-student interactions because students were looking to the professor or teaching assistant to provide guidance and support. Nevertheless, they found these online activities extremely valuable because they could help, guide, and support individual students through their field experiences, and also received feedback that students felt less isolated as a result.

\section{FACULTY DECISIONS WHEN USING ONLINE ACTIVITIES IN TEACHER EDUCATION COURSES}

Whether the online activities were pre-class, post-class, or supplemental to class instruction, all ten faculty members interviewed in this study reflected that they had to take the following decisions a) when first using online activities in a course, b) when adapting online activities for a different online tool (e.g. moving from an online discussion board to a blog) or c) when adapting online activities for a different course that they taught.

\section{How should online activities be structured?}

All the professors interviewed considered it important to structure the online communication space and provided substantial structure for online activities. Six of the ten faculty interviewed always provided a discussion prompt or a question when using online discussions in their courses. They posed a question that they found crucial to student understanding of the course topics and provided a resource e.g. an online video or podcast that they asked students to discuss. Two faculty members experimented with letting students post discussion questions for the week and act as discussion leaders. While one professor found that very satisfying, the other professor decided against it in future offerings of the course, because she thought that students should discuss topics she found important for the course.

The remaining four faculty members interviewed preferred to allow students to either post reactions to readings or find resources to post on the blog, and allowed pairs of students to lead the discussion or summarize the discussion. One professor provided a format to students - they had to name the reading, formulate a question, and summarize their reasons for asking the question. Professors who required groups to find and present resources online also provided a clear format for the group, sometimes providing an example as a model. One professor who used a blog to have students share their project ideas and comment on each others' projects, created specific areas on the blog and provided a templatelike structure where students could do so.

In moving from online discussion boards within a learning management system to a wiki and to a blog, two professors initially tried to replicate what they had done before. While the professor who used the wiki moved to a less-structured and more student-driven format in subsequent offerings of the course, the professor who used a blog found the sequential nature of the blog irritating and difficult to structure. She reverted back to using an online discussion board in her courses because she could structure activities for each week in advance. 


\section{How should online groups be formed?}

The decision to form groups or have students contribute individually was another dilemma faced by the professors, because they could not initially conceive of all the students interacting with one another online. Four professors preferred to use online groups because students would then interact closely with each other - "they might get to know people they wouldn't normally know that are outside of their program and who in class, they might not normally sit with or talk to." To this end, two professors assigned the groups very "deliberately" but differently. While one chose students from different programs or who were preparing to teach different grades for each group, the other professor grouped together students with similar interests and backgrounds. The first professor reasoned that students would have exposure to other subject-matter and grades:

I assign students to a group...it's very intentional. There are students from different programsfrom the special education program, from early childhood, from elementary education, some who are interested in the primary grades, some who are interested in the intermediate grades. I set them up very deliberately with one from each of the specializations to the extent possible so that the groups are meant to be diverse in terms of their teaching interests, their disciplines of study, etc.

Two professors who initially asked graduate students to form their own groups in the first course where they included group activities decided against it in later courses. They found that not only was it timeconsuming when students formed the groups, but that some students were left out, or were dissatisfied with the groups, which affected student participation.

\section{Should online activities be mandatory and graded?}

Eight of the ten professors interviewed in the study required online activities as part of the course assessment and allotted between $10 \%$ and $40 \%$ of the course grade to online activities. Students sometimes had the option of participating in online discussions for a certain number of weeks or could choose their "best six weeks out of ten" to be graded. Students in groups were always given the same grade, except for those taught by one professor, who required peer evaluation as part of the grade to determine participation and contribution by students in a group. Although the mandatory nature of online activities "raised the level of discussion," professors found it more time-consuming to grade these activities than to read them.

\section{What guidelines would help students succeed online?}

All the faculty members who were interviewed asserted that very clear instructions on the syllabus, on the course website, wiki, or blog, as well as explanations in class were very important to students' completing online activities properly individually or in groups. All the professors provided instructions about acceptable use of language and many of them set expectations by providing a model posting, a grading rubric, and examples of unacceptable contributions. Eight out of ten professors set a deadline for postings, including a day of the week and the time. One professor stated,

You're going to have to make students extremely accountable every week, and you're going to have to find some way to hold them accountable. So what I did was I set a deadline. And the reason I did that was that everyone in class knew that after that time, they could go to that thread and see everybody's response that was going to be there, if they were going to respond or...Having that knowledge ahead of time gave the course a nice structure. 
Deadlines ensured that professors had time to read student contributions, that other students could comment on peer contributions, and that a student or group could summarize the contributions for the face-to-face class.

\section{How often should the professor participate online?}

Four of the ten faculty members interviewed never participated in the online activities although they answered student questions that were addressed to them in the online discussion board, wiki, or blog. They reasoned that it was a space for students to interact with each other and not with them - "I didn't want to interpose myself between the students. I wanted it to be their own thing." Two professors reflected that they found it difficult at first, but they learned over time to let the students talk to each other or explain concepts to each other online. They found this satisfying because in the classroom, students always addressed their comments to the professor, and the professor found it difficult not to "sway the discussion the way I want it to go." Nevertheless, they made it very apparent to the students that they were reading or "watching" their online interactions, and often referred to the online activities in class. All the other professors "jumped in" to clarify terms and concepts that students did not understand or had misinterpreted. One professor described it as,

I could really hone in on what they were getting right and what they were getting wrong and say, let's pick up on this point. Now I'd really like you to think about how $x, y$, and $z$ relates to

Professor A's presentation on this and the classroom in the video we watched two weeks ago, and what does this all mean?

\section{FACTORS INFLUENCING FACULTY DECISIONS WHEN USING ONLINE ACTIVITIES}

Faculty members in this study reported changes in their instruction as they gained experience using online activities and as they migrated to new technologies. While they continued to provide structure and guidelines to students, they found that as they continued to use online discussions, wikis, or blogs for student interaction, they "controlled" the interactions or "intervened" less and less, allowing students to "take it and run with it." They solicited student feedback and were gratified that students perceived the same benefits of online activities to classroom instruction that they did. In addition to their own experiences using these technologies, the factors that formed the basis of the professors' decisions to use online activities in different ways were class size, the course level (undergraduate or graduate), and the content and format of classroom sessions in a course.

\section{Class size}

The number of students in a class was a decisive factor in the professors' decisions about whether students would do individual or group work, whether students would be required to comment on each others' work, and whether the professor participated online. One professor participated often in a small class with 20 students, where students posted individually and were required to post comments or resources weekly, but decided to only read students' contributions in a large class of $80+$ students where she required students to post only seven out of 14 weeks in the semester. Describing the responses in the larger course as "overwhelming", in a subsequent offering of the course the professor designed group activities that required students to solve only four problems in groups during the semester instead of responding to readings individually. Another professor divided up the discussion groups according to the Teaching Assistants' sections in a class of over 100 students, where the Teaching Assistants interacted 
intensively with the individuals in the group and the professor commented once a week on each group's work online.

\section{Course goals and Course level}

One professor described the difference between his undergraduate and graduate courses as the students' prior knowledge of a subject and "the life experience" they brought to course activities. He is comfortable discussing the format of his online activities with students in a doctoral seminar, and designing collaborative writing activities online that "the students drive." However, in his Master's level courses he provides clear structure and deadlines for activities that are very focused on weekly course content. Another professor stated that she participated more and was "looking for higher-level thinking" in online activities in her graduate courses whereas she wanted students to apply course content and "situate readings in a broader context" in her undergraduate courses. Professors thus designed online activities differently and set different expectations depending on the course level, course goals and course content.

\section{Content and Format of Classroom Instruction}

The amount of time that was needed and available for professor-student interaction or studentstudent interaction influenced many professors' decisions to use online activities or virtual space for interaction. In lecture-based classes, or classes with guest speaker presentations, professors required students to post their reflections or responses online in order to "know that they are thinking." One professor stated that it bothered him that he "delivered" content in the classroom so he exploited the online discussion board to allow students to talk, ask questions, and relate the content to a bigger context. In contrast, two professors reflected that in discussion-based seminars where students interacted a lot in the classroom, they were challenged to come up with online collaborative projects that were worthwhile for students to complete and that deepened or broadened students' understanding. They wanted to integrate online activities because they considered online collaboration and group work to be valuable to students in real life, where students were increasingly required to work individually and as members of a team in a virtual environment. They also wanted their students to be exposed to online activities that could be used in their future classrooms.

Four professors struggled with deciding which parts of the curriculum students should engage with online and which topics should be reserved for the classroom. One professor pointed out that when she first used online discussions, students were discussing the same topics in class, which was not very useful. In the last couple of years she has consciously worked towards choosing topics for online activities or problem-solving, and topics that she feels require classroom time. Another professor experimented with asking students to complete a group task online as well as in the classroom during different weeks in the semester and asked for student feedback on the usefulness of each medium. Three professors reported changes in their classroom instruction as a result of the online activities. They began asking students to complete some of the activities they had been doing in the class online, thus freeing up time for new activities in the classroom.

\section{DISCUSSION AND IMPLICATIONS FOR EDUCATORS}

Out of the 23 courses included in this research, 16 used online discussion boards or group discussion areas in learning management systems, four used blogs, and three used wikis. Faculty commented on several benefits of online activities that were discussed in previous research - increased participation by all students, exposure to different aspects of course content, continuation of course topics and conversations outside the classroom, and reflection (Angeli, Bonk, \& Valanides, 2003; Barnett, 2006; 
Ferdig \& Roehler, 2004; Kian-Sam \& Lee, 2008; Hough, Smithey \& Evertson, 2004; Jenning, 2005; Jetton, 2004; Lee-Baldwin, 2005; Lord \& Lomicka, 2007; Maher \& Jacob, 2006). In addition, they reported increased familiarity with students' understanding of course content and individual problems. The professors in this study especially found online group activities useful to make it possible for students to "think with each other" and to take the attention away from the professor - "it's not about me anymore, it's about them and the readings." Furthermore, they consider it extremely important for their students to participate and succeed at such activities in order to better prepare them for the real world where virtual collaboration and communication are now ubiquitous. Due to these perceived benefits, faculty continue to find ways to use online discussions and online group work as means to engage students, migrating to new technologies but retaining the structure and goals of their online assignments.

All ten professors in this study began using online activities within the learning management system provided to them at their university. Four of those professors later tried to apply the same strategies that they had used in an online discussion board or in online group spaces to wikis or blogs. Although the attributes of the technology (e.g. the wiki) caused the professors to adapt their strategies and instructions to students, the types of online activities they used and the scaffolding that they provided to students did not change. It follows that the different examples provided in this chapter can largely be adapted to newer technologies in courses with similar instructional goals or content. In experimenting with online activities, the faculty members moved from a professor-controlled environment to a more student-controlled environment, and became more comfortable allowing the students to lead the discussion or restructure the virtual space. Provision of structure and guidelines, as well as professor monitoring of online activities, however, remained very important regardless of the student-centered nature of online activities.

Professors in this study leveraged their pedagogical knowledge and skills as well as their prior experiences with technology to structure online activities to supplement their on-campus courses. They took several decisions when combining online components and classroom instruction. The analysis of the qualitative data highlighted the importance of four main factors for decisions made by faculty members in the different courses they taught - the number of students, the type of course (e.g. course level, content, and goals), students' prior knowledge of course content, and classroom activities. The time taken to read, provide feedback, and integrate students' online work into classroom instruction can be a challenge for professors in courses with a large number of students. Online group work, lesser number of activities or giving students the option of completing activities only for a certain number of weeks during the semester could be considered by educators teaching large courses. Appointing discussion leaders or discussion groups who are responsible for different topics can also be an effective way of engaging large numbers of students. Discussion leaders or discussion groups can be asked to summarize and synthesize resources or discussion content either online or in the classroom. Students in smaller courses can take on specific roles in online activities, can carry out peer evaluations and provide feedback to one another, and can also contribute new resources about course topics.

The goals, the subject matter, and the level of courses (basic or advanced; undergraduate, graduate, or doctoral) influence the ways in which faculty structure and participate in online activities. If professors want students to engage with certain concepts e.g. universal design, at a beginners' level, they can provide easier scenarios that students can analyze and solve in groups online whereas in a doctoral seminar, students can be expected to introduce a scenario for their peers to analyze and discuss. While students are completing a practicum, online journals, blogs, or activities based on field experiences can be far more helpful than online discussion threads, especially if students are not comfortable sharing their experiences with all their peers. Topics that require students to identify types of instruction or skills can benefit from activities where students analyze and discuss online videos or podcasts. When students have prior knowledge of topics or have already worked in schools e.g. as in-service teachers or administrators, it is easier for professors to implement online activities that involve application of course content to real- 
world environments. Online activities that involve student contribution of resources like videos or podcasts work especially well for courses where the professor expects students to tie the instruction to a larger context, or relate it to trends, standards, or policies.

When deciding to use online student interactions in face-to-face courses, educators should review their plans for classroom instruction, thus deciding whether students would learn best by completing the activities before or after each classroom session. The format can be varied depending on the format for a class session. For example, during a week when there is a guest speaker, the professor can decide to have a post-class online activity. If the professor uses class time to lecture, he/she can decide if students should discuss readings online before the class, thus allowing her/him to prepare and adapt his/her lecture The professor may also decide that after a lecture, the students should comment on the lecture and describe how the content connects to course topics. Dividing up course topics for discussion and interaction online and in the classroom can be an effective use of both online and classroom time, because students can easily become bored or weary of repetitive topics online and in the classroom.

\section{DIRECTIONS FOR FUTURE RESEARCH}

This research highlights ways in which a small group of teacher educators use current technologies as integral to the pedagogy of a course and course activities, thus modelling certain strategies and decisions that are not dependent on the technology used for online activities but on the outcomes that they hope to achieve. Teacher educators' use of online activities or online discussions in their courses acquaints students with the use of online tools for teaching and exposes them to the experience of working online individually or in a group before they design and use online activities in their classrooms. Pre-service or in-service teachers are thus better prepared to use similar tools in their teaching, and become more sensitive to students' participation or problems as a result of their participation in online activities. The combination of online and classroom activities in higher education may yield substantial benefits to students and their learning.

As the Web-based component of on-campus courses in higher education increases, the choices that instructors make when using online activities in their courses become more important, as do the strategies that they employ when using online technologies. Teacher educators are experts at pedagogy so future research should focus on identifying: a) the ways in which they use online technologies, b) the activities they design for students to interact online, c) the types of guidelines and structure that they provide when teaching with online technologies and the outcomes thereof, and d) how they evaluate student participation in those online activities. The ways in which online activities are used by faculty when teaching online courses could also inform educators seeking to integrate such activities into face-toface instruction. Notwithstanding the value of individual case studies, studying the evolution and refinement of online activities by faculty members in multiple courses, when they use different technologies for online activities, and use these over a period of time could also be beneficial for beginning educators.

Each professor in this study reflected on lessons learned from his/her experiences e.g. using online discussions or structuring online groups in a certain way, providing examples from different courses and stressing the importance of pedagogical strategies that could leverage the capabilities of new technologies and yet be applied when using multiple technologies. The identification of such activities and strategies that can be adapted and applied when using newer technologies could inform other faculty and teachers wishing to use new technologies in teaching other disciplines. As online technologies become more sophisticated, educators will continue to adapt and apply these strategies to podcasting, audio or video communication tools, and virtual environments. Studying how much they learn from past 
experiments with online technologies, and what factors influence their decisions to use certain technologies over others would be useful to teacher developers and instructional designers engaged in the integration of new technologies in higher education.

\section{REFERENCES}

Angeli, C., Valanides, N., \& Bonk, C.J. (2003). Communication in a web-based conferencing system: The quality of computer-mediated interactions. British Journal of Educational Technology, 34(1), 31-43.

Barnett, M. (2006). Using a web-based professional development system to support preservice teachers in Examining Authentic Classroom Practice. Journal of Technology and Teacher Education, 14(4), 701-29.

Biesenbach-Lucas, S. (2003). Asynchronous discussion groups in teacher training classes: Perceptions of native and non-native students. Journal of Asynchronous Learning Networks, 7(3), 24-33.

Bower, M., Woo, K., Roberts, M., \& Watters, P. (2006). Wiki Pedagogy - A Tale of Two Wikis. Paper presented at the $7^{\text {th }}$ conference on Information Technology based Higher Education and Training, Sydney, Australia. 187-198.

Christopher, M.M., Thomas, J.A., \& Talent-Runnels, M.K. (2004). Raising the bar: Encouraging high level thinking in online discussion forums. Roeper Review, 26(3), 166-171.

Dietz-Uhler, B., \& Bishop-Clark, C. (2002). The psychology of computer-mediated communication: Four classroom activities. Psychology Learning and Teaching, 2(1), 25-31.

Engstrom, M.E., \& Jewett, D. (2005). Collaborative learning the wiki way. TechTrends, 49(6), 12-15.

Fauske, J., \& Wade, S.E. (2003). Research to practice online: Conditions that foster democracy, community, and critical thinking in computer-mediated discussions. Journal of Research on Technology in Education, 36(2), 137-154.

Ferdig, R.E., \& Roehler, L.R. (2003). Student uptake in electronic discussions: Examining online discourse in literacy preservice classrooms. Journal of Research on Technology in Education, $36(2), 119-136$.

Garrison, D., Anderson, T., \& Archer, W. (2000). Critical inquiry in a text-based environment: Computer conferencing in higher education. Internet and Higher Education, 2(2-3), 87-105.

Garrison, R. \& Kanuka, H. (2004). Blended learning: Uncovering its transformative potential in higher education. Internet and Higher Education, 7(2). 95-105.

Gilbert, P.K., \& Dabbagh, N. (2005). How to structure online discussions for meaningful discourse: a case study. British Journal of Educational Technology, 36(1), 5-18.

Gorski, P., Heidlebach, R., Howe, B., Jackson, M., \& Tell, S. (2000). Forging communities for educational change with e-mail discussion groups. Multicultural Perspectives, 2(4), 37-42.

Hara, N., Bonk, C.J., \& Angeli, C. (2000). Content analysis of online discussion in an applied educational psychology course. Instructional Science, 28(2), 115-152.

Hough, B.W., Smithey, M.W., \& Evertson, C.M. (2004). Using computer-mediated communication to create virtual communities of practice for intern Teachers. Journal of Technology and Teacher Education, 12(3), 361-86.

Jenning, H. (2005). Increasing value without increasing effort? The use of WebCT in accompanying face-to-face lectures under the constraint of low budget. Journal of Distance Education, 20(2), 78-84.

Jetton, T.L. (2004). Using computer-mediated discussion to facilitate preservice teachers' understanding of literacy assessment and instruction. Journal of Research on Technology in Education, 36(2), 171-91.

Kian-Sam, H. \& Lee, J.C. (2008). Postgraduate students' knowledge construction during asynchronous computer conferences in a blended learning environment: A Malaysian experience. Australasian Journal of Educational Technology, 24(1), 91-107. 
Kumar, S. (2007). Professor Use, Facilitation, and Evaluation of Asynchronous Online Discussions in On-campus Courses. In C. Montgomerie \& J. Seale (Eds.), Proceedings of World Conference on Educational Multimedia, Hypermedia and Telecommunications 2007 (pp. 2855-2863). Chesapeake, VA: AACE.

Lee-Baldwin, J. (2005). Asynchronous discussion forums: A closer look at the structure, focus and group dynamics that facilitate reflective thinking. Contemporary Issues in Technology and Teacher Education, 5(1), 93-115.

Lord, G. \& Lomicka, L. (2007). Foreign language teacher preparation and asynchronous CMC: Promoting reflective teaching. Journal of Technology and Teacher Education, 15(4), 51332.

MacArthur, C.A. (2006). The effects of new technologies on writing and writing processes. In C.A. MacArthur, S. Graham, \& J. Fitzgerald (Eds.), Handbook of writing research (pp. 248-262). New York: Guilford.

Maher, M. \& Jacob, E. (2006). Peer computer conferencing to support teachers' reflection during action research. Journal of Technology and Teacher Education, 14(1), 127-150.

Meyer, K.A. (2002). Quality in distance education: Focus on on-line learning. Hoboken, NJ: JosseyBass.

Oliver, M. \& Trigwell, K. (2005). Can 'Blended Learning' be redeemed? E-Learning, 2(1), 17-26.

Overbaugh, R.C. (2002). Undergraduate education majors' discourse on an electronic mailing list. Journal of Research on Technology in Education, 35(1), 117-139.

Phillipson, M. \& Hamilton, D. (2004). The romantic audience project: A wiki experiment. Retrieved November 22, 2007, from

www.rc.umd.edu/pedagogies/commons/innovations/rap/toc.htm

Raman, M., Ryan, T., \& Olfman, L. (2005). Designing knowledge management systems for teaching and learning with wild technology. Journal of Information Systems Education, 16(3), 311-320.

Schaff, M. (2003). Student perceptions of technology and how it impacts their learning: A technology integration experience. In Proceedings of World Conference on Educational Multimedia, Hypermedia and Telecommunications (pp. 1764-1768). Chesapeake, VA: AACE.

Schellens, T., \& Valcke, M. (2006). Fostering knowledge construction in university students through asynchronous discussion groups. Computers \& Education, 46(4), 349-370.

Slavit, D. (2002). Expanding classroom discussion with an online medium. Journal of Technology and Teacher Education, 10(3), 407-423.

Vaughan, N., \& Garrison, D.R. (2005). Creating cognitive presence in a blended faculty development community. Internet and Higher Education, 8(1), 1-12.

Vess, D.L. (2005). Asynchronous discussion and communication patterns in online and hybrid history courses. Communication Education, 54(4), 355-364.

Wu, D., \& Hiltz, S.R. (2004). Predicting learning from asynchronous online discussions. Journal of Asynchronous Learning Networks, 8(2), 139-152.

Young, J.R. (2002). "Hybrid" teaching seeks to end the divide between traditional and online instruction. Chronicle of Higher Education, 48(28), A33. 